\title{
O DESAFIO DO DESENVOLVIMENTO LOCAL SUSTENTÁVEL NA ERA DA GESTÃO DAS COMPETÊNCIAS
}

\begin{abstract}
Resumo: A globalização tem-se processado sob os auspícios de uma conjugação de fatores desencadeados pela abertura comercial, pela criação de um mercado financeiro internacional, pelas potencialidades das novas tecnologias da informação $e$ da comunicação e, ainda, de uma ação política coordenada pelas grandes economias mundiais ( $G 8$ e G 20), sem que desta coordenação tenha resultado, aos olhos da opinião pública, uma diminuição substancial da injustiça social e um melhor controlo de 4 grandes crises: a económica, a financeira, a social e a ecológica. $O$ caminho da interdependência global parece, entretanto, sem retorno. Apontase, neste texto, a necessidade da ação cidadã dos atores sociais no sentido de conjugar a atividade económica e social (multilateral e estatal) com uma nova governação dos territórios locais, potenciando os recursos humanos e combatendo a exclusão com base na gestão de organizações produtivas adaptadas ao trabalho em redes, sob a liderança de agências vocacionadas para a emergência de uma cultura de projeto, integradora das diferenças.
\end{abstract}

Albino Lopes ${ }^{1}$

Palavras-chave: Economia Global e Cidadania; Exclusão Social; Organizações Adhocráticas; Projeto Individual; Liderança de Agências em Rede.

Title: THE CHALLENGE OF LOCAL SUSTAINABLE DEVELOPMENT, IN THE ERA OF MANAGEMENT SKILLS

\begin{abstract}
Globalization has been done under the auspices of a combination of several factors. Among these we highlight the trade liberalizations, the creation of an international financial market, the new technologies of information and communication and also a political action coordinated by the major economies (G8 and G20). Nevertheless, in the eyes of the public opinion, this coordination does not result in a substantial decrease of social injustice and a better control of the 4 big crises: economic, financially, social and ecological. The path of global
\end{abstract}

\footnotetext{
${ }^{1}$ Professor Catedrático, do Instituto Superior de Ciências Sociais e Políticas da Universidade de Lisboa. Email: alopes@iscsp.ulisboa.pt
} 
interdependence seems, however, with no return. In this context, it is necessary to promote the action of social actors, in order to combine economic and social activity (multilateral and public) with the local areas, developing the human resources and fighting social exclusion, based on the management of organizations, adapted to work on networks, under the leadership of specialized agencies in the emergence of a local integrated project of a culture program.

Key Words: Economic globalization and local economy; social exclusion; adhocratic organization; individual project; leadership network.

\section{INTRODUÇÃO}

O termo desenvolvimento local, inserido no título do trabalho, quando associado à economia social, indica uma opção pela produção de riqueza suportada em valores de serviço ao homem todo, ou seja, pela defesa de um duplo projeto organizacional capaz de compatibilizar a dimensão económica e a social. Expressa ainda a convicção de que as organizações aderentes a este modelo têm condições para competir e ganhar espaço face àquelas que se orientam apenas pelo lucro. $\mathrm{O}$ ponto de vista que defendemos implica o desenvolvimento de uma cultura de rede interorganizacional, ancorada em territórios aprendentes, geridos de maneira a tirarem partido dos únicos recursos que verdadeiramente contam: pessoas comprometidas e apostadas em desenvolver continuamente as suas competências. Pretendemos, deste modo, refletir sobre a realidade económico-social dos territórios, sem questionar nomenclaturas tão diferentes como economia solidária ou $3^{\circ}$ sector, mas assumindo que a economia formal seria definida como o desenvolvimento de condições adequadas à criação de riqueza a partir da interação de indivíduos, dotados de competências múltiplas. A economia tornar-se-ia social ou solidária, não através de uma estratégia de manipulação de classificações jurídico-políticas, mas porque interconecta indivíduos e organizações que se propõem criar redes inclusivas, enquadradas por instituições de crédito e instituições educativas, tomando a forma de agência e com a missão de gerar situações efetivas de igualdade de oportunidades nos territórios de referência.

A associação da economia social à noção de cidadania pretende sugerir que a essência da condição humana se traduz e operacionaliza por uma conceção do indivíduo, como sujeito ativo do seu projeto de vida, enquanto pessoa em busca do sentido da sua existência, com todos os deveres e direitos inerentes a essa mesma condição.

A opção pela abordagem institucional (no sentido de Enriquez, 1992) pretende evidenciar a associação entre desenvolvimento e valores, mais do que à mobilização de condições materiais e organizacionais. 
Privilegiam-se, desse modo, as dimensões de uma eficaz liderança política daquilo que adiante designaremos de "território aprendente", por contraposição à maior importância acordada às dimensões de gestão profissional das organizações ditas de economia social.

De acordo com Sorman (2008), deve-se a A. Sen (o conhecidíssimo prémio Nobel indo-britânico) a identificação de 5 critérios intangíveis e não quantificáveis (designados como liberdades instrumentais) geradores de desenvolvimento económico: a liberdade política; as capacidades económicas; as oportunidades sociais; uma segurança protetora; garantias firmes de transparência. Na nossa opinião, esta abordagem de Sen conforta, igualmente, de maneira poderosa a abordagem institucional que propomos, porquanto as garantias e os valores referidos só se enraízam socialmente a partir de instituições sobre os quais se fundam e que os sustentam de modo indiscutível.

Para uma caracterização do problema central das instituições da economia social vocacionadas para o apoio a populações carenciadas, partimos da ideia, que tem sido igualmente explorada por autores como Messu, de que a pessoa em busca de competências, quando se encontre na condição de assistida, construiria de modo inevitável uma identidade específica (e um estatuto de pessoa dependente, suportado na ideologia do "direito a " sê-lo), no contexto da relação psicológica de "transferência" com o técnico/organização de assistência. Seria, pois, da qualidade a conseguir com esta relação que a pessoa assistida derivaria, igualmente, as suas estratégias de saída para a condição de autonomia ou de manutenção durável dessa mesma condição de dependência.

Uma organização de economia social trabalharia deste modo no fio da navalha entre a relação de dependência e a relação de busca da autonomia através da formação e do desenvolvimento de competências, pelo que não servira de muito esconder que a atividade própria da relação de ajuda envolve uma ambiguidade de base, portadora de estigma social, segundo o qual uma pessoa assistida será sempre suspeita de desenvolvimento de uma estratégia de dissimulação com a finalidade de evidenciar a sua penúria insuperável de recursos.

Uma relação de ajuda dotada de garantias de qualidade, que consiga evitar completamente a armadilha do estigma social, a qual por definição poderia ocorrer com qualquer pessoa, e ao mesmo tempo permitir-lhe o acesso ao direito inalienável de ser considerado como pessoa necessitada de ajuda (porque é a qualidade da relação que permite evitar que a pessoa caia na situação de estigmatizada), tal nos parece ser o desafio de uma rede social de organizações vocacionadas para o apoio às pessoas carenciadas, mas em conexão com as atividades da economia formal de bens e de serviços. 
No interior da relação de ajuda, competiria à figura do facilitador ajudar a criar as condições que conduzam à descoberta de um projeto de vida e/ou profissional, por parte da pessoa carenciada, que deste modo se apropriaria do seu próprio destino enquanto pessoa em busca de referências autoproduzidas. Pela sua relevância pensamos que seria indispensável citar a Constituição sobre a Igreja no Mundo Atual, do Concílio Vaticano II, que, no capítulo 69, sintetiza deste modo dois mil anos de pensamento sobre a função social da riqueza produzida na terra: é dever de todos alimentar o que morre de fome ou ser culpado do seu assassínio; todos devem, na medida das suas possibilidades, ajudar os pobres, tanto os indivíduos como os povos. Acrescenta depois a finalidade da mesma ajuda, conferindo uma inquestionável profundidade de projeto à relação de ajuda: "para que eles possam ajudar-se por si próprios e desenvolverem-se posteriormente".

Pretende-se, com a reflexão que propomos, alicerçar as bases de uma análise crítica das formas organizativas e da qualidade que têm caracterizado as organizações vocacionadas para a relação de ajuda, bem como a legitimação e o enquadramento institucional em que habitualmente essa relação ocorre.

\section{GLOBALIZAÇÃO DA ECONOMIA, O DESENVOLVIMENTO LOCAL E O REENCONTRO COM A NOÇÃO DE PESSOA RECURSO: O PROBLEMA DA RECENTRAÇÃO DE UM DEBATE NECESSÁRIO}

Os últimos 25 anos do século XX, na sequência da grande crise de 1973/75 que coincidiu com o designado primeiro choque petrolífero, foram já vividos, num contexto de globalização acelerada das trocas comerciais, empurrada pelas novas tecnologias da informação e da comunicação. $\mathrm{O}$ fenómeno ganhou, entretanto uma amplitude sem precedentes, em termos de globalização dos mercados financeiros, criando as bases para oscilações perturbadoras e mais ou menos incompreensíveis, até para aqueles que teriam por missão regular esses mercados.

As consequências do processo de globalização atingiram progressivamente proporções crescentes, pontuadas por crises económicas cíclicas e que geraram uma sociedade desunida, face à necessidade humana de recriar em cada geração a sua esperança no futuro. A passagem da responsabilidade da criação de uma resposta adequada a este desafio para o Estado transformado em Estado Social pode ser questionada como sintoma e causa da mesma crise. Forjou-se uma resposta estática (a ideia de uma distribuição equitativa da riqueza, 
por parte do Estado, sem a contrapartida do dever da sua criação) para uma situação económica cujo controlo escapa ao Estado.

O que é menos visível, entretanto, é que este fenómeno da globalização tem sido acompanhado de uma consequência que poderíamos classificar como de reação antiética e que mereceria muito mais atenção do que aquela que lhe foi dada durante mais de uma década e meia. Esta traduzir-se-ia na redescoberta do território como base de vida económico-social, e do modo de produção artesanal, como tendência sustentada, a ponto de alguns autores avançarem com a ideia de "glocalização" para traduzir a realidade com a qual nos estamos a confrontar. Existiriam, ainda, reflexos positivos em ordem a um reencontro entre o trabalho e o trabalhador, dissociados desde há muito pelo modo de produção industrial, ampliado pelo taylorismo no decurso do século XX.

A economia encontra-se, efetivamente globalizada, potenciada pela tecnologia e pelo mercado, tendo esta nova realidade aberto espaços mais amplos a um desenvolvimento sustentado com base territorial, ancorada num tipo de indivíduo criativo e capacitado para trabalhar em redes organizacionais.

Estes seriam os termos de um problema, cuja solução passaria pela capacidade de pensar o atual contexto socioeconómico de forma integrativa (Enriquez, 1992), e não como realidades antagónicas. Os problemas que a globalização coloca aos indivíduos, em termos de direito ao trabalho e, por essa via, de acesso ao rendimento, não podem encontrar solução durável ao nível organizacional (dominado com frequência mais pela cultura de competição do que de cooperação), mas antes através da capacidade integrativa de redes interorganizacionais. É a nova economia de rede (Lopes e Moreira, 2004) que poderá ganhar as condições indispensáveis para reunir a muitíssimo ampla pluralidade de interesses e de meios locais, e incentivar a sua aposta na manutenção de um equilíbrio indispensável entre a competição pela criação de riqueza e a união pelo cimento da solidariedade, da cooperação e da coesão social, ao nível da envolvente territorial.

A hipótese geral de partida é de que as tendências de síntese entre os três fatores, ação global, pensamento local e aposta no capital humano, estão efetivamente presentes no contexto da revolução operada pela tecnologia e pela abertura global dos mercados, podendo essas mesmas tendências ser contrariadas ou potenciadas, com resultados diametralmente opostos, consoante a gestão da economia dos territórios que for desenvolvida a nível institucional. Com a tecnologia do passado, o desenvolvimento assumia a configuração de polos irradiadores sob forma concêntrica. As tecnologias atuais permitem a multipolaridade, 
tudo dependendo da forma como a coesão social se tornar em valor instituinte (a questão dos valores parece ser determinante) ao nível dos diversos territórios, pela compatibilização da competição criadora do liberalismo tradicional, com a cooperação e economia em rede de que se tratará adiante.

A obsessão de algumas classes dirigentes locais pela procura de atividades geradoras de grandes volumes de trabalho por conta de outrem, ao invés de apostas equilibradas centradas no desenvolvimento das competências das pessoas, pode levar as populações desses territórios a um ciclo vicioso de gastos enormes em termos de financiamento público em busca de um "desenvolvimento" que se descobre, normalmente pouco tempo depois, não ter condições de sustentabilidade.

\section{O ESPAÇO INSTITUCIONAL E A AÇÃO DOS DIRIGENTES POLÍTICOS LOCAIS}

O espaço institucional, constituído pelas redes de partenariados organizados sob o modelo de "agências locais de desenvolvimento" que adiante se explica, pode ser estruturado segundo duas noções de estratégia de ação coletiva: a resultante de planificação (à priori) e a emergente ( posteriori). Por sua vez, este modelo organizacional implica, necessariamente, uma liderança de natureza política, no sentido geral e mais amplo do termo, a qual se pode ainda distinguir em transformacional (inspiradora de uma visão partilhada por todos) ou transacional (centrada na capacidade pessoal de influência através do recurso ao prémio ou à promoção).

Parece óbvio que os líderes associativos locais são, em primeiro lugar, tentados a conduzir a ação dos atores sociais através do recursos a ações limitadas, de natureza política e/ou simbólica: paradigma da ação "para" as pessoas.

O paradigma da ação "com" as pessoas, ao invés, consistiria em montar um processo interpretativo da realidade a transformar (explicitação, conceptualização de lógicas, realização e questionamento), tendente a concentrar meios e vontades num pequeno número de situações possíveis.

O importante neste processo parece ser a conceção da pessoa como fonte de soluções, como pessoa - recurso, e não como súbdito, sendo cidadão apenas porque e quando se depende do seu voto político. 


\section{DA PRODUÇÃO DE COMPETÊNCIAS À PRODUÇÃO DE CONTROLO SOCIAL}

Este paradigma da ação "com" os sujeitos pretende, assim, clarificar uma distinção crucial, entendida como corolário da distinção, atrás referida, entre trabalho e trabalhador, enquanto elemento fundador de uma visão polémica e não-apologética da economia social. O trabalho e o trabalhador apenas se encontram reunidos quando, e se, a atividade exercida for simultaneamente produtora de empregabilidade, ou seja, geradoras de competências que garantam à pessoa a autonomia para a procura do seu espaço de realização. Pensar o inverso equivale a pactuar com aquilo que se tem convencionado designar de alienação interna, para a distinguir da alienação externa, desde há muito denunciada pelas correntes marxista e/ou pela doutrina social da Igreja Católica.

Parece, entretanto, existir um consenso muito alargado segundo o qual o emprego produtivo de bens e serviços vendáveis está em rápida diminuição face às disponibilidades crescentes de tempo livre e às necessidades de atualização de saberes e de competências, dada a revolução tecnológica que tem subvertido as bases dos saberes tradicionais. A máquina impõe-se ao homem, como desde há muito, autores como A. Gorz ou R. Debray têm chamado a atenção. Esta necessidade socioeconómica de compensar a destruição sistemática de trabalho tem criado dificuldades muito sérias à manutenção do emprego nos sectores produtivos, conduzindo os sujeitos à necessidade de procederem a uma reactualização de competências. Na ausência desta atualização, os sujeitos correm o risco de caírem numa situação que pode ser descrita como de necessidade de controlo social, cujas instituições principais seriam de natureza assistencial, psiquiátrica ou prisional, para evocar as categorias de M. Foucault e, mais recentemente, de P. Lascoumes, que, desde os anos 80, fala a este respeito de um "processo de cancerigenização social", o qual seria, ainda, financeiramente incomportável a prazo. Procurar construir sobre este processo "perverso" uma ação socialmente responsável, parece inadequado para criar as bases de uma resposta à crise atual, quer do ponto de vista racional quer do ponto de vista ético.

A definição de economia social, de acordo com o ensaio de classificação que propomos, não está associada nem à atividade nem ao tipo de entidade a que pertence a iniciativa, mas antes à condição existencial em que se encontra o utente. O utente é aqui assumido numa aceção muito abrangente, considerando-se, ainda, que este intervém como produtor das suas próprias competências, em lugar de assumir uma 
condição de consumidor passivo, como no caso do paradigma da ação "para".

Assiste-se, de facto, ao nascimento exponencial de organizações públicas, privadas ou associativas, formadas para se ocuparem de toxicodependentes, de deficientes, de ex-reclusos, de idosos, de semabrigo, de refugiados, de emigrantes, de vítimas de diversos tipos de violência, ou seja, de categorias de sujeitos discriminados negativamente, quase sempre tratados como "súbditos", ou seja, de utentes considerados como incapazes, na prática, de formular um projeto que os reconduza à situação de pessoas - recurso. Emergência de um projeto de vida e ação facilitadora de organizações produtoras de competências.

Consideramos a questão do projeto de vida de uma pessoa fragilizada o aspeto nodal de toda a reflexão acerca da economia social. É precisamente a noção de projeto, que faz do utente das organizações de economia social, não um súbdito privado de mobilidade e de expressão livre, nem um cliente consumidor de serviços, mas um cidadão com capacidade de determinação do rumo da sua vida em consonância com a sua identidade.

Admitindo que todo o ser humano é portador de um projeto de vida, que o próprio tem por vezes dificuldade em identificar e realizar, um dos recursos críticos para as regiões radicaria na existência de organizações facilitadoras, que conseguissem responder às necessidades de cada sujeito, sem descurar a resposta ao grande número de pedidos, que a evolução da economia dita formal continua a fazer crescer.

Receber gratuitamente uma casa que se mendigou seria, então, um ato social de destruição das possibilidades de criação de um sonho familiar de encontrar meios de realização do sonho, logo de destruição de competências e de manutenção das hipóteses de criação de assistencialismo. Propõe-se designar este fenómeno como de controlo social, no sentido que lhe atribui P. Lascoumes, como atrás referimos.

Quais as alternativas ao modelo assistencialista?

A hipótese que poderia ser avançada é a de que valeria a pena considerar que todo o apoio económico constitui uma situação de crédito com obrigação de retorno, à imagem do que tem sido sugerido pelo criador do conceito de microcrédito (Yunus), e entender essa formulação como arma eficaz contra a pobreza e a mendicidade. Se esta proposta foi considerada uma inovação social de largo alcance, nos países pobres, porque motivo têm optado os países mais desenvolvidos pela noção de direito à "esmola" pública, geradora de desresponsabilização cívica? Parece-nos ser perfeitamente possível reorganizar uma instituição de tipo misericórdia, por exemplo, que tem prestado ajuda a pessoas carenciadas, de forma a levar estas pessoas fragilizadas a candidatar-se/levantar as mesmas ajudas sob a modalidade de microcrédito, associado, este, por 
sua vez, a um sistema de seguro de crédito para incobráveis. Perguntarse-á se existe verdadeira diferença? Pensamos que este dispositivo organizacional é suscetível de uma mudança profunda, tanto na atitude dos técnicos como dos cidadãos utentes carenciados. Efetivamente, em lugar de se centrarem na estratégia de deteção dos indícios de dissimulação para poderem formular a convicção de estarem face a uma pessoa realmente carenciada, os técnicos passariam a valorizar as possibilidades de pro-atividade dos cidadãos carenciados, vendo-os como pessoas-recurso, enquanto estas, seriam estimuladas a desenvolver atitudes conducentes à transformação das dificuldades em "desejo" de saída (pela via da sublimação, em sentido freudiano) da condição de "devedores sociais crónicos" e de aspiração ao reconhecimento social das suas competências.

Não se pense, entretanto, que estas posturas dissimulatórias, em espelho, entre técnicos e pessoas assistidas são raras. Testes de situação, com recurso a entrevistas inspiradas no método do "cliente mistério", conduzidas sob nossa supervisão, confirmam esta relação de tipo mimético, em que o técnico conduz a pessoa carenciada pela via do subsídio dependência e esta interioriza o direito e o estatuto de pessoa assistida. Impõe-se, por isso, a via da sublimação, transformando a dificuldade em oportunidade de formulação de projeto.

Da nossa experiência de vida como jovem estudante, em França, nos anos 60, gostaríamos de referir que testemunhámos a chegada em massa de camponeses pobres, vindos das aldeias portuguesas, quase analfabetos, e que deram origem a uma comunidade bem integrada, empreendedora e abastada, nos dias de hoje, mais próspera, inclusive, do que a generalidade da população residente naquele território, a acreditar em estudos da especialidade. Como é possível, então, que hoje em dia, com meios incomparavelmente superiores, se permita que fiquem agarradas ao círculo vicioso da miséria gerações de pais, filhos e netos, sem que se promova uma reflexão - ação que dê suporte a um pensamento alternativo acerca do futuro desta disciplina que se tem designado de economia social? A resposta parece-nos poder estar relacionada com o facto de que, naqueles tempos difíceis, de todos os pontos de vista, o meio envolvente dos territórios rurais pobres portugueses era qualificante, ao passo que hoje não temos sido capazes de promover a essa mesma condição qualificante ou aprendente as instituições dos nossos bairros suburbanos. Sanjit Bunker Roy, fundador do Barefoot College, no Rajistão indiano, parece testemunhar uma visão aproximada. Diz o célebre pedagogo, em conferência pronunciada no início de 2009, ma Escola de Negócios da AESE, em Lisboa, que a educação (entendida como o que se recebe da comunidade e do ambiente em que se vive) 
específica das famílias pobres da sua região permite às pessoas resolver os seus problemas e usar as suas capacidades físicas e mentais para tornar operatórios os seus saberes. Qual a função da escola, então? Ensinar a conservar bens essenciais, tais como a água, a aprendizagem da utilização da energia solar e, porque não, as disponibilidades da informática, mas tudo isso na condição de conservar as instituições do passado, sem as deixar desvirtuar pela gestão ocidental de empresas e de escolas. Estas reflexões colocam-nos face à necessidade do questionamento dos valores institucionais das nossas organizações de solidariedade, e principalmente da função atribuída à "Escola" como instituição garante da igualdade de oportunidades. A instituição Escola não é assumida, nesta análise crítica, como uma "instituição do passado", não sendo por isso garantia de igualdade de "capacidades fundamentais para vir a poder beneficiar dos bens disponíveis", na formulação de Sen (2009). Esse seria, porventura, o papel da família "tradicional" socialmente integrada? Boff (2005) não hesita em o afirmar com veemência, denunciando aquilo que designa de ideologia da exclusão do pai como sustentáculo da família, substituindoo, diríamos nós, pela ideologia da igualdade pelo assistencialismo. $\mathrm{Na}$ base da reflexão de Boff poderíamos acrescentar que a ideologia do assistencialismo evoca, antes, a figura maternal da dependência e do receber sem a exigência do retribuir. Sorman (2008), apoiando-se na abordagem teórica do grande economista Sala-i-Martin, denuncia igualmente a assistência económica a África como uma forma de encerrar os africanos num estatuto de dependentes. Jacques Delors, com a autoridade que se reconhece como um dos mais influentes pensadores da Europa e do mundo multipolar, não hesita, igualmente em defender a reconstrução do Estado-Providência, sobre o investimento massivo naquilo que designaríamos de sistema público integrado de "proteção à primeira infância" como forma de garantir a todos o acesso à igualdade de capacidades (Delors e Dollé, 2009).

A noção de "Agência" (responsável pela gestão das oportunidades que levem à igualdade de capacidades, ou de competências, como preferimos dizer) que abaixo propomos, procura ser a expressão da formulação de uma estratégia baseada nos recursos internos existentes numa organização ou numa coletividade, na linha de Barney (1991) e de Barney et al. (2001), a qual parece conduzir, de forma subliminar, as já citadas reflexões de Sanjit Bunker Roy.

É o sonho/projeto, nascido da vontade de transformar dificuldades em oportunidades, essa arma que parece verdadeiramente adequada para combater contra a dependência? A nossa resposta é afirmativa, tal como a de L. Boff. É no contexto da interação Pai-Mãe que a Criança, como corrobora o autor, vai potenciar o sonho capaz de a projetar para a iniciativa e a criatividade de forma a ultrapassar as dificuldades, pelo 
desenvolvimento de competências empreendedoras ao longo da sua vida. Acreditando, sobretudo, na sabedoria popular segundo a qual, "a necessidade (quando encontra o sonho) potencia o engenho", procuramos situar a nossa proposta na senda de uma reconstrução do projeto das pessoas em dificuldade para desenvolverem o respetivo projeto profissional e de vida em contexto intra-organizacional, enquadrado numa ótica de economia territorializada, como teremos ocasião de teorizar mais em pormenor.

Vale a pena, ainda, desmistificar a questão do microcrédito enquanto solução generalizada. Não parece ser a fórmula financeira em si que produz os efeitos de que fala o conhecido Prémio Nobel. A sua experiência fundadora ocorre num contexto em que as mulheres pobres são um grupo social minoritário e coeso, com um grande sentido de confiança recíproca e com uma forte aptidão para inventar soluções de sobrevivência para si e para os filhos, habituadas a contactar com elas próprias, numa sociedade masculina, no sentido de G. Hofstede. O empreendedorismo individual, no contexto da experiência de Yunus e na situação portuguesa, por exemplo, não tem paralelo possível, dada a política de recompensar de preferência os que nada se propõem fazer para sair da situação de carência. A mensagem de Yunus questiona em profundidade o nosso modo de pensar a relação de ajuda. Procurando interpretá-la à luz da corrente conhecida como psicologia skinneriana, aquela que nos parece mais adequada para interpretar comportamentos determinados por interesses medíveis, diríamos que Yunus encontrou no ambiente cultural do seu povo, uma das regiões mais pobres do subcontinente indiano, o veículo para premiar comportamentos individuais criativos e geradores de riqueza, com as consequências coletivas desejáveis, na linguagem de Richelle (1993). E em Portugal, como poderíamos encontrar uma saída que premiasse os comportamentos desejáveis? A resposta a esta questão pode, no nosso entender, determinar o futuro de uma sociedade portuguesa solidária e economicamente sustentável.

\section{PROJETO INSTITUCIONAL E ORGANIZAÇÃO FACILITADORA}

As organizações cuja finalidade ou missão se centra nas "pessoas com necessidade de ajuda" tomam, por regra, a configuração de burocracias profissionais, onde o poder é exercido, não tanto por uma direção, mas, de um modo muito mais efetivo, pelos quadros técnicos, que asseguram a execução das tarefas, para as quais se encontram habilitados por 
qualificações adequadas, na base da pirâmide ou do "centro operacional", para utilizar os termos de H. Mintzberg.

Este tipo de organizações são referenciadas como sendo próprias de hospitais, universidades, e outras afins, e são consideradas como difíceis de gerir, dada a tendência para que a estratégia a que obedecem se estabelecer na base da pirâmide, sendo, ainda, muito difícil que se desenvolva no seu seio uma centralidade no utente, como deveria ser sempre o caso da economia social.

Impõe-se, por isso, uma inovação permanente, ao nível da (re)estruturação das organizações da economia social, e da sua liderança, com o propósito de conceder a centralidade à necessidade (e sobretudo ao desejo) de conduzir a pessoa assistida à aprendizagem de si, que temos igualmente visto desenvolver por Messu, de quem já falámos atrás.

Uma burocracia profissional "pura" parece ser, pois, inadequada para garantir o trabalho técnico de uma equipa multidisciplinar, ao serviço do encontro da pessoa carenciada com o seu próprio projeto, entendido como o resultado de um "balanço de competências", experienciado na relação com a pessoa do profissional facilitador, o qual, por sua vez, teria como suporte toda uma relação de apoio por parte de uma equipa mais vasta, vocacionada para a compreensão da complexidade da rede social envolvente, e que dê profundidade à história de vida da mesma pessoa carenciada.

A noção de competências é de abordagem muito difícil e encontra-se envolta numa polémica interminável. O nosso propósito é o de contribuir para a sua definição, mas para o efeito, não dispomos do tempo necessário. Seria questão, nomeadamente, de convocar conceitos da psicologia insuficientemente tratados, nos trabalhos que conhecemos, e questioná-los de maneira sistémica. Noutros estudos temos abordado o assunto com outra profundidade, pelo que apenas afloraremos aqui o tema de uma forma resumida, procurando situar os conceitos que possam permitir um enquadramento mínimo e se possa entender o modelo que propomos. Assim, partimos dos conceitos: de inteligência (entendida como relação sujeito - objeto, capaz de manipulação operativa, com os limites físicos que se impõe conhecer, segundo a perspetiva piagetiana); de afetividade (como uma relação "sujeito - sujeito", impossível de manipulação e de conhecimento objetivo, segundo os estudos de $\mathrm{H}$. Wallon); e de emoção (como relação do sujeito para consigo próprio, em ordem ao controlo dos seus medos e tensões, na ausência do qual ficaria perturbada tanto a questão cognitiva como a afetiva). À luz desta abordagem sistémica do conhecimento do mundo exterior ao sujeito, seria possível definir competências como o desenvolvimento de um projeto profissional e de vida, refletido em interação com uma instância facilitadora, suscetível de retirar a sua energia emocional dos seus sonhos 
e dos recursos acumulados, nomeadamente os de carácter cognitivo (saberes), com vista a uma autonomia, a uma cooperação e a um controlo das situações, que lhe permita um enquadramento social desejável.

O principal problema destas burocracias profissionais é a distância cultural abissal que separa os quadros técnicos prestadores do "serviço de ajuda" e as pessoas com necessidade. O recurso a facilitadores voluntários foi surgindo com mais ou menos espontaneidade, mas sempre associado a uma difícil articulação com os técnicos e restante pessoal de apoio.

Uma segunda ordem de dificuldades prende-se com o elevado número de pessoas a atender, tornando-se difícil levar em conta a trajetória de vida e a necessidade de ganhar confiança sem a qual é impossível a emergência de um projeto de vida.

A terceira dificuldade prende-se com os elevados níveis de stresse ocupacional (bournout) que se apodera dos quadros técnicos, os quais, para se defenderem psiquicamente, despersonalizam a relação, passando a olhar os utentes como números. Convirá ainda ter em consideração a diferença de códigos de linguagem e de referências culturais entre técnicos e pessoas carenciadas, sendo crucial a ponte que as pessoasmodelo poderiam representar. Se já passaram pelo mesmo e saíram da situação de carência, estas representam um trunfo formidável para a organização. $\mathrm{O}$ seu voluntariado teria um valor inestimável, dada a sua proximidade cultural com a pessoa carenciada. Nas circunstâncias atuais de fomento do assistencialismo, cada pessoa assistida representa uma ocasião de formação de outras que procuram saber como se obtém o máximo de ajuda sem que os técnicos desconfiem. Com uma reformulação do modelo organizativo e estratégico da ação/relação de ajuda, cada êxito constituiria uma fonte de aprendizagem e de sustentabilidade do desenvolvimento local a partir do desenvolvimento das competências sociais da comunidade "mutualista" dos beneficiários do mesmo microcrédito.

Para responder a estas dificuldades/potencialidades, a hipótese de mudança e desenvolvimento organizacional, em ordem à formação de adhocracias de quadros técnicos especializados em relação de ajuda, suportados por uma organização mais ampla organizada como uma burocracia profissional, apareceu-nos como sendo o modelo desejável.

Entendemos que a ação dos quadros técnicos deveria consistir, segundo o modelo proposto, em detetar e formar uma (ou, de preferência, um grupo) pessoa-modelo, próxima culturalmente da pessoa-alvo ou pessoa-recurso como igualmente a temos designado, com uma trajetória de vida ascendente, após relação de ajuda havida, que procurasse estimular o 
desenvolvimento de um projeto de vida, com recurso à aprendizagem por modelagem, de acordo com a visão epistemológica da psicologia da aprendizagem, a partir do princípio da modelagem, de A. Bandura.

O mundo está ávido de poder aumentar exponencialmente os espaços de gratuidade (voluntariado), de saberes úteis e de conhecimento, bem como de uma cidadania responsável, como defende Attali (2004). A política que institucionalizou o Estado Social europeu, porém, tem alargado os espaços sem trabalho, isto é, sem o correspondente alargamento dos espaços de produção de competências. A nossa sociedade tem ultrapassado a exclusão pela via do ter, diz ainda o autor; mas pobre será cada vez mais a condição de "não-pertença", a ausência de capital relacional ou social.

O nosso propósito será, sobretudo, o de ajudar a situar o espaço do voluntariado no seio das organizações produtivas, tornando o trabalho profissional uma fonte de expressão solidária. Não menosprezamos o outro voluntariado; o nosso ponto de ancoragem é o da Gestão de Recursos Humanos (GRH) que aceita repensar a responsabilidade social e a introduz na matriz da estratégia organizacional. (O caso da professora que, em complemento da sua atividade letiva, estuda o problema do aluno em revolta destrutiva contra o pai, ou dos técnicos de orientação vocacional do Instituo de Emprego e Formação Profissional - IEFP, com os quais experienciamos mais de uma centena de histórias dramáticas de vida, os quais foram incentivados e treinados a conceder tempo seu, para além do trabalho de entrevista de colocação a que estão obrigados, para escutarem em profundidade os projetos de vida de desempregados, em busca de autoestima e não apenas de trabalho dependente, servir-nos-ão de modelo geral, para articular "adhocracias" de técnicos e de voluntários).

Algumas das etapas previstas, no desenrolar da metodologia de elaboração dos projetos de vida, poderiam tirar partido do trabalho de grupos multidisciplinares de quadros técnicos, na linha do que o esquema aqui proposto deixa entender. Esta multidisciplinaridade dos quadros técnicos justifica-se pela necessidade de responder à conceptualização da noção de "competências" como uma realidade multidimensional, revelada/desenvolvida em contexto organizacional, tal como se pretendeu demonstrar no ponto anterior.

As grandes organizações assistenciais, entretanto, quase sempre organizadas como burocracias mecânicas, poderiam encontrar nesta proposta um modelo de inspiração para a sua transformação em verdadeiras redes (a nível interno e/ou externo) de organizações facilitadoras da ação assistencial em ordem à sua (re)formulação como estruturas facilitadoras da emergência de projetos de vida. É de salientar que, de acordo com a perspetiva de H. Mintzberg, numa burocracia 
mecânica os técnicos atuam segundo normas ditadas de cima para baixo, enquanto numa burocracia profissional, como a que resultaria do enquadramento que propomos, a ação dos técnicos resulta de protocolos que os próprios desenvolvem em conjunto a partir das suas experiências e saberes profissionais em busca de um questionamento científico permanente. A questão que se levanta, neste contexto, é a da liderança das organizações enquanto tal, mas também, e sobretudo, da liderança da rede local de todas as organizações que seria necessário coordenar e articular para dar sentido à necessidade de desenvolvimento dos projetos de vida e/ou profissionais das pessoas fragilizadas (que cada organização só por si não teria em princípio condições de concretizar), ao nível das organizações existentes nos territórios em causa. Insistimos neste ponto porque fora de um contexto organizacional qualificante não é possível identificar e tomar autoconsciência das competências próprias. É igualmente no contexto da autonomização de atividades existentes e/ou a criar que são possíveis as condições de êxito, e não a título de empreendedorismo individual como se faz habitualmente.

\section{PARA UMA MODELIZAÇÃo DA FIGURA DE AGÊNCIA LOCAL DE DESENVOLVIMENTO}

As organizações, no interior de um determinado território, estão submetidas a um duplo processo de competição e de cooperação, o qual nem sempre é evidente para os atores implicados.

De igual modo, nem sempre competem pela melhoria da eficiência ou cooperam pelos melhores motivos (cartelização, nomeadamente).

No que respeita ao mercado do emprego, este processo bipolar é particularmente evidente na disputa pelos profissionais mais qualificados (tendo em vista a eficiência produtiva) e na dispensa de trabalhadores pouco qualificados, situação que cria um mercado de trabalho dual, tendo como consequências, a rarefação dos profissionais e a abundância de serventes com baixos salários de que beneficiam o conjunto dos empresários. Por seu lado, este processo incentiva a subcontratação, a preconização e as formas de trabalho atípicas, associadas a um risco maior de exclusão e de degradação do meio social envolvente, com prejuízo para todos.

A emergência da sociedade dual, cujo desenvolvimento parece longe de um controlo desejável, inscreve-se como um dos maiores obstáculos ao desenvolvimento sustentável das regiões, nomeadamente das áreas suburbanas das grandes cidades.

Um dos desafios maiores dos nossos tempos consiste na procura de modelos de desenvolvimento local sustentável. Os esforços, animados por 
associações de desenvolvimento, tendentes a fazer emergir redes e partenariados interorganizacionais e interempresariais, começa a dar frutos animadores, impondo-se o seu estudo e problematização.

A missão destas "agências locais de desenvolvimento", poderia ser definida como instrumento e guia de formas de cooperação e de competição, ou seja, orientadas no sentido da valorização das competências com a mão-de-obra local, da formação de redes de interesses produtivos e comerciais, da criação de sistemas de crédito mútuo e, em simultâneo, da estimulação de uma competição salutar com base na inovação e na eficiência dos processos de trabalho.

Parece consensual a ideia de que a competição interorganizacional é indispensável à criatividade e à eficiência dos processos de trabalho, mas que, em simultâneo, gera riscos de exclusão dos elos sociais mais fragilizados. A cooperação interempresarial gera, por seu lado, ganhos de eficiência, pelo que liberta meios humanos. Só uma criatividade permanente a nível empresarial parece poder gerar as condições de um desenvolvimento com coesão social. A inovação exige, entretanto, uma preparação profissional longa e um suporte financeiro adequado.

A coesão social, enquanto valor instituinte de um território, é, por sua vez, um poderoso fator de sustentabilidade da atividade empresarial, pelo que a "agência local de desenvolvimento" poderá assumir a forma de partenariado sustentado por empresas, serviços públicos, autarquias e instituições educativas com vista a estimular a cooperação de empresas afins (pelo território partilhado ou pelo ramo de atividade), a forma de jovens, ativos e desempregados, o controlo dos meios financeiros gerados pela atividade económica e os meios institucionais de inserção social e de elaboração de projetos viáveis, com reflexos, a curto prazo ou médio prazo, no emprego.

É inevitável que a luta política ou mesmo partidária atravesse estas formas organizativas, com a consequente desordem daí decorrente. Mas esse será o preço que as sociedades abertas pagam pela inovação social.

O nível institucional de análise proposto pretende refletir, assim, a unidade de ação e a estratégia possível a construir, pelas instituições com responsabilidades sociais locais, conhecedoras da realidade a transformar. Não se veja nesta opção como uma defesa de um qualquer novo funcionalismo de tipo regionalista, mas antes a adesão a uma conceção mais cooperativa da atividade organizacional local, sem, evidentemente, deixar de reconhecer à competição e à abertura de mercado o seu lugar na procura da eficiência produtiva. Uma espécie de "coopetição", misto de competição cooperativa ou de cooperação competitiva, poderia ser o lema desta atividade institucional a desenvolver, para garantir a emergência da economia em rede proposta por R. Reich, no início dos anos 90, como 
antídoto à crise da economia competitiva, que acabaria por chegar, entretanto.

\section{LIDERANÇA POLÍTICA E TRANSFORMACIONAL DA AGÊNCIA LOCAL DE DESENVOLVIMENTO}

No que respeita à liderança deste tipo de redes constitutivas desta noção de "Agência", que designamos sob a noção de "agência local de desenvolvimento", gostaríamos de apresentar, como base e referência teórica da hipótese que pretendemos formular, o trabalho de pesquisa que temos vindo a desenvolver acerca da noção de "equipa de liderança". A perspetiva teórica de maior alcance parece ser aquela que aponta para a noção de uma equipa de liderança de três tipos de líderes: um com perfil mais federador e garante de uma confiança resiliente entre todas as partes interessadas; um segundo, com um perfil de inovador e mais vocacionado para a criação de soluções e obtenção de recursos no exterior do quadro local; e, como complemento dos dois primeiros, um líder com um perfil técnico, de controlo rigoroso de meios e de resultados.

O papel (e missão de cada um dos membros da equipa de liderança) parece depender das relações de poder entre os três perfis de líderes apresentados, tornando-se fundamental perspetivar quer uma "escola de formação de liderança", quer a definição de um papel de condução política da agência e do equilíbrio entre os três tipos de perfis. Os autores desta abordagem teórica (H. Mintzberg e P. Pitcher), bem como as nossas próprias pesquisas, apontam para a necessidade de a equipa ser conduzida pelo perfil que designamos como líder mais federador, ou artesão, como tem sido caracterizado na literatura científica (Lopes e Moreira, 2004). É este perfil de líder artesão que parece revelar-se capaz de gerar uma confiança generalizada, pelo menos no que respeita à relação dual, com a totalidade dos atores pertinentes do meio envolvente. É necessário ter em consideração, entretanto, que o líder com perfil de artesão não se impõe com facilidade no caso de ter como competidores potenciais outros líderes com perfil de artista e menos ainda com líderes de perfil tecnocrático. Lopes e Moreira (2004), no seguimento de P. Pitcher, falam, a este propósito, do "apagamento" do líder com perfil de artesão como constituindo um verdadeiro "drama da liderança", dado que o perfil necessário (o líder artesão de perfil relacional) não se impõe e impõe-se aquele que não gera a necessária confiança entre atores pertinentes para garantir a intercooperação (o líder tecnocrata com perfil de controlo e de poder). Daí que se torne necessário colocar a hipótese da necessidade da presença de um líder político, com a estrita missão de definir quem deverá ser o quê, nestas tarefas de liderança de uma agência/rede 
interorganizacional. A razão de ser da nossa hipótese baseia-se no facto de que, se mesmo em culturas de elevada confiança como é o caso do país natal da autora citada (Canadá), o fenómeno é crítico, a escolha de um perfil adequado se deve revelar ainda mais problemática no contexto português caracterizado pela cultura de baixa confiança, no sentido que $\mathrm{F}$. Fukuyama confere ao conceito em causa.

\section{CONCLUSÃO}

Pela dimensão que a economia social ganhou entre nós, como contraponto (legitimação?) à globalização de que falámos no início desta reflexão, a tarefa primordial parece-nos dever estar associada à preparação de líderes que coloquem em perspetiva este tipo de atividade, que saibam enquadrar organizações em rede, flexíveis e abrangentes, no seio dos territórios em causa, que mobilizem o voluntariado de pessoas que funcionem como recurso, em lugar de pensarem a atividade apenas como ação de profissionais e que saibam prevenir (e não estimular) situações que configuram controlo social e não desenvolvimento de competências.

Entendemos por esta noção de "escola de liderança das organizações da economia social" algo de muito diferente do que se poderia definir como uma "escola de gestão", no sentido mais tradicional do termo. Para transformar as organizações da economia social existentes, refundandoas, propomos a noção de "escola de formação de líderes carismáticos", no sentido paulino do termo (ou mosaico, como dizem Reto e Lopes (1991), retomando uma reflexão de S. Moscovici):

- Aptos a olhar, em equipa, a realidade local, com as suas organizações e as suas oportunidades, e a conceber e promover uma cultura de coesão territorial;

- Capacitados para assumir que a articulação em rede, é a melhor forma de gestão das organizações, quando os líderes destas não veem senão relações hierárquicas e/ou de comércio;

- Disponíveis para a promoção, em cada uma destas, de um tipo de organização do trabalho como meio de obtenção de empregabilidade e não apenas de emprego;

- Persuasivos na procura da articulação da atividade produtiva das empresas com organizações solidárias, que nelas colocariam estagiários em formação (trabalho protegido), para o desenvolvimento de competências;

- Promotores de ação voluntária para que, em conjunto com técnicos competentes, pessoas - modelo ajudem carenciados a reapropriarem-se da sua autonomia e sentido de projeto. 
Inspira-nos, nesta reflexão, o exemplo tantas vezes incompreendido, do padre basco José Arrismendiarreta, que perante o desemprego do seu território, pegou no dinheiro disponibilizado pelas esmolas recolhidas na paróquia pobre de Mondragón e criou uma cooperativa para não deixar encerrar uma pequena fábrica de candeeiros a petróleo, condenada pela eletrificação da Espanha franquista. Entendeu esta experiência como uma atividade formativa de jovens (apenas 5 , inicialmente) alunos da sua aula de moral, começando uma atividade de reparação de todo o tipo de artigos eletrodomésticos na zona. O dinheiro era depositado numa "Caixa" fundada para dar suporte a toda a atividade produtiva, sem cedências à atividade especulativa nem deixando que o dinheiro sirva outro fim que não o que deriva das necessidades da coletividade que produziu a riqueza. Num momento em que o essencial da atividade financeira se tem orientado para a "multiplicação" especulativa do dinheiro, em que as próprias instituições do Estado intervêm com alguma displicência, vale a pena evocar a ética que este exemplo de Mondragón representa, e que faz recordar a sabedoria infinita que se esconde pela "Palavra" que há dois mil anos desafia a mentalidade capitalista, acerca da imensa riqueza contida "no óbolo da viúva"2, fecundado pela visão inspiradora e instituinte de um empreendedor social da têmpera de José Arrismendiarreta.

Balizada entre a escola e a caixa económica local, foram nascendo atividades produtivas tão variadas quanto as competências das pessoas o permitia, dando origem ao maior grupo produtivo sob a fórmula cooperativa do mundo. A Fundação Peter Drucker tem classificado esta experiência organizacional como portadora do mais elevado significado empresarial de sempre e como exemplo a seguir no desenvolvimento de uma economia simultaneamente competitiva e solidária. Neste âmbito, o grupo empresarial cooperativo Mondragón desenvolve todos os projetos pela via do designado intra-empreendedorismo, sendo este o modelo mais eficaz que se conhece (Cf. Womack et al., 1990), no que respeita à sustentabilidade dos projetos, ao invés do empreendedorismo individual, cuja taxa de sucesso é meramente residual. É este modelo que nos serve de inspiração quando propomos a figura de agência, para colocarmos o

\footnotetext{
${ }^{2}$ Não são os grandes meios que desenvolvem os povos e os indivíduos mas o modo como estes reagem aos desafios das dificuldades (poupando o pouco que se tem, disponibilizando-o para o investimento reprodutivo, à imagem dos pioneiros do cooperativismo de Rochedale). Responder às dificuldades com a segurança das soluções facilitísticas só pode conduzir à regressão humana e material, como recordava Claude Tresmontant, reinterpretando as teorizações do grande historiógrafo A. Toynbee. (Ver: crónica - L'histoire et son interprétation, 1978 - in, La voix du Nord).
} 
problema da sua conceção, da liderança e da confiança que esta inspira, nos diversos atores a implicar no meio envolvente.

Gostaríamos, entretanto, deixar bem vincada a ideia de que não está em questão, nesta breve abordagem de uma realidade tão complexa como esta, qualquer juízo de valor sobre as formas organizacionais que a inspiração dos dirigentes associativos tem permitido desenvolver. Temos a certeza, porém, de que toda a cedência no que respeita aos valores institucionais de autonomia e de responsabilidade, que enformam as organizações de economia social, legitimadas pela assistência ao ser humano fragilizado, constituiria um retrocesso evidente, a nível societal. $\mathrm{O}$ assistencialismo, de que se trata nesta reflexão, seria equivalente à recusa ou à ausência de reconhecimento do direito do ser humano a ser tratado, pelas instituições ditas de economia social, como uma verdadeira pessoa - recurso à procura do seu projeto, e tudo isto feito sob a capa daquilo que nos atrevemos a classificar como um humanismo irrefletido. Quereríamos, igualmente, vincar, com a ênfase que nos for possível colocar nesta reflexão, que é possível, sempre, trabalhar, com técnicos e com pessoas carenciadas, no desenvolvimento de um projeto de vida, que não pactua com a exclusão nem com o arrastar de vidas sem sentido, não legitimando formas de pensamento e de ação desresponsabilizantes de familiares ou de responsáveis empresariais ou políticos, sendo, para isso, necessário pensar de forma inovadora a identidade e a liderança das organizações da economia social, em estejamos e/ ou devamos estar envolvidos.

\section{BIBLIOGRAFIA}

Aubert, N. e De Gaulejac, V. (1992). Le côut de l'excellence; Paris: Seuil; Attali, J. (2004). La voie humaine: pour une nouvelle social-democratie. Paris: Fayard;

Barney, J. B. (1991) Firm resources and sustained competitive advantage, in Journal of Management, vol 17, $\mathrm{n}^{\mathrm{o}} 1$, p.99-120;

Barney, J. B., Wright, M. e Ketchen Jr., D. J. (2001) The resource-based view of the firm: ten years afte 1991, in Journal of Management, vol 27, p. 625-641;

Boff, L. (2005). São José: A Personificação do Pai. Campinas: Verus Editora;

Delors, J. e Dollé, M. (2009). Investir dans le Social. Paris: Odile Jacob; Enriquez, E. (1992). L'Organisation en Analyse. Paris: PUF; 
Gajardo, M. (2000). Ivan Illich, in Prospects: the quarterly review of comparative education, International Bureau of Education, vol. XXIII, no. 3/4, 1993, p. 711-20;

Lopes, A. e Moreira, P. (2004). A Liderança e a Cooperação InterPME's em Portugal - Um Estudo Longitudinal. Porto: Associação Empresarial de Portugal.

Reto, L. e Lopes, A. (1992). Liderança e Carisma: O Exercício do Poder nas Organizações. Lisboa: Editorial Minerva;

Paschohoal, T. e Tamayo, A. (2004). Validação da escala de stresse no trabalho; in Estudos de Psicologia;

Prahalad, C. K. (2006). The Fortune at the Bottom of the Pyramid: Erradicating Poverty Through Profits - Enabling Dignity and Choice Throuh Markets. Pennsylvania: Wharton School Publishing;

Richelle, M. (1993). Du nouveau sur l'esprit? Paris: P.U.F;

Sen, A. (2009). The Idea of Justice; Cambridge: Harvard University Press;

Sorman, G. (2008). L'économie ne ment pas; Paris: Fayard.

Sue, R. (1991). De la Sociologie du Loisir à la Sociologie des Temps Sociaux; in Societés, 32 (3/4), p. 173-181;

Todd, E. (2002). O fim do império; Lisboa: Publicações Europa América;

Womack, J.P., Jones, D.T. \& Roos, D. (1990). The Machine that Changed the World. New York: MacMillan Publishing Co. 